\title{
Pressure dependence of the band gap energy for the dilute nitride $\mathbf{G a N}_{\mathrm{x}} \mathrm{As}_{1-\mathrm{x}}$
}

\author{
Chuan-Zhen Zhao ${ }^{1, *}$, Tong $\mathrm{WeI}^{2}$, XiaO-Dong Sun $^{1}$, Sha-Sha Wang ${ }^{1}, \mathrm{Ke}$-Qing Lu ${ }^{1}$ \\ ${ }^{1}$ Tianjin Key Laboratory of Optoelectronic Detection Technology and Systems, School of Electronics and Information \\ Engineering, Tianjin Polytechnics University, Tianjin, 300387, China \\ ${ }^{2}$ College of Science, Civil Aviation University of China, Tianjin, 300300, China
}

\begin{abstract}
A model is developed to describe the pressure dependence of the band gap energy for the dilute nitride $\mathrm{GaN}_{\mathrm{X}} \mathrm{As}_{1-\mathrm{x}}$. It is found that the sublinear pressure dependence of $\mathrm{E}_{-}$is due to the coupling interaction between $\mathrm{E}_{+}$and $\mathrm{E}_{-}$. We have also found that $\mathrm{GaN}_{\mathrm{x}} \mathrm{As}_{1-\mathrm{x}}$ needs much larger pressure than GaAs to realize the transition from direct to indirect band gap. It is due to two factors. One is the coupling interaction between the $\mathrm{E}_{+}$and $\mathrm{E}_{-}$. The other is that the energy difference between the $\mathrm{X}$ conduction band minimum $(\mathrm{CBM})$ and the $\Gamma \mathrm{CBM}$ in $\mathrm{GaN}_{\mathrm{x}} \mathrm{As}_{1-\mathrm{x}}$ is larger than that in GaAs. In addition, we explain the phenomenon that the energy difference between the $\mathrm{X} C \mathrm{CBM}$ and the $\Gamma \mathrm{CBM}$ in $\mathrm{GaN}_{\mathrm{X}} \mathrm{As}_{1-\mathrm{x}}$ is larger than that in GaAs. It is due to the impurity-host interaction.
\end{abstract}

Keywords: GaNAs; band gap energy; pressure dependence; dilute nitride

(C) Wroclaw University of Technology.

\section{Introduction}

$\mathrm{GaN}_{\mathrm{x}} \mathrm{As}_{1-\mathrm{x}}$ has attracted much attention due to its interesting electronic properties and potential applications in microelectronic and optoelectronic devices. Unlike the conventional III - V semiconductor alloys, the band gap energy of the dilute nitride $\mathrm{GaN}_{\mathrm{x}} \mathrm{As}_{1-\mathrm{x}}$ decreases rapidly relative to that of bulk GaAs despite the fact that the band gap energy of GaN is much larger than that of GaAs [1-5]. The rapid reduction of the band gap energy can be described by the band-anticrossing (BAC) model $[3,4]$. It should be noted that the BAC model is not only proposed to describe the composition dependence of the band gap energy for the dilute nitride $\mathrm{GaN}_{\mathrm{x}} \mathrm{As}_{1-\mathrm{x}}$, but is also proposed to describe its pressure dependence. Although the BAC model describes the band gap energy of the dilute nitride $\mathrm{GaN}_{\mathrm{x}} \mathrm{As}_{1-\mathrm{x}}$ alloy depending on composition as well as pressure, there are still several problems which should be further investigated. The

*E-mail: as3262001@ aliyun.com first one is that the BAC model is too simple to interpret the optical properties of the dilute nitride alloys because many effects are not included in the model. The second one is that more and more evidences prove that $\mathrm{E}_{+}$(the optical transition between the valence band and the second conduction subband) for the dilute nitride alloys evolves from the splitting of the L conduction band minimum (CBM) rather than the $\mathrm{N}$ level [6-8], which makes some scholars doubting whether it is reasonable to use the BAC model to explain the formation of $\mathrm{E}_{+}$and $\mathrm{E}_{-}$(It is the $\Gamma$ conduction band of the dilute nitride alloy. It also corresponds to the band gap energy of the dilute nitride alloys). In addition, there are three coupling interactions in $\mathrm{GaN}_{\mathrm{x}} \mathrm{As}_{1-\mathrm{x}}$. One is the impurity-host interaction, another is the impurity-impurity interaction, the other is the host-host interaction. Deng et al. [5] considered that the BAC model should be expanded to include the impurity-host interaction, host-host interaction and the impurity-impurity interaction to give a complete description of the band structure of the dilute nitride alloys. In order to solve the above problems, we have developed a model. 
The model can describe the pressure dependence of the band gap energy for the dilute nitride $\mathrm{GaN}_{\mathrm{x}} \mathrm{As}_{1-\mathrm{x}}$ very well.

\section{Physical model and discussion}

Before presenting the model, let us analyze the band evolution of the dilute nitride $\mathrm{GaN}_{\mathrm{x}} \mathrm{As}_{1-\mathrm{x}}$. When the $\mathrm{N}$ content is very small, incorporation of $\mathrm{N}$ in GaAs can introduce an isolate $\mathrm{N}$ level. With increasing the $\mathrm{N}$ content, on the one hand, two or more $\mathrm{N}$ atoms may be bonded to one $\mathrm{Ga}$ atom, leading to the formation of $\mathrm{N}-\mathrm{N}$ pairs (containing two $\mathrm{N}$ atoms in the vicinity) and $\mathrm{N}$ clusters (three or more $\mathrm{N}$ atoms are included). These configurations correspond to different $\mathrm{N}$-related impurity states and have different self-energy values, lower than the isolated $\mathrm{N}$ level [9]. On the other hand, these N-related impurity states mix with the states of the host material and form the mixed states. We can call them alloy states. When the $\mathrm{N}$ content is up to $0.2 \%$, the band $\mathrm{E}_{+}$is formed [3]. Under this condition, the mixing between the Nrelated impurity states and the host states is not sufficient. As the energy levels of the localized impurity states depending on pressure are much weaker than that of the extended host states, we can distinguish the energy levels of the localized and extended states by their different pressure behaviors. When the $\mathrm{N}$ content is large enough, the mixing between the N-related impurity states and the host states is sufficient. The alloy states are very stable. Under this condition, the applied pressure can no longer separate the N-related impurity states from the alloy states as distinct levels. The energy levels which different states correspond to cannot be distinguished by pressure [10].

Fig. 1 shows the pressure dependence of $\mathrm{E}_{+}$ and $\mathrm{E}_{-}$for $\mathrm{GaN}_{0.015} \mathrm{As}_{0.985}$ [11]. It can be seen that both $\mathrm{E}_{+}$and $\mathrm{E}_{-}$move to higher energy as the pressure increases. However, an obvious difference between them can be found. The experimental data show that band $\mathrm{E}_{+}$increases superlinearly with increasing pressure while the pressure dependence of $\mathrm{E}_{-}$is sublinear with a tendency of saturation at high pressure. It is also found that when the pressure is low, the increase of $\mathrm{E}_{+}$is lower than that of $E_{-}$. When the pressure is large enough, the situation is contrary. The increase of $\mathrm{E}_{-}$is lower than that of $\mathrm{E}_{+}$.

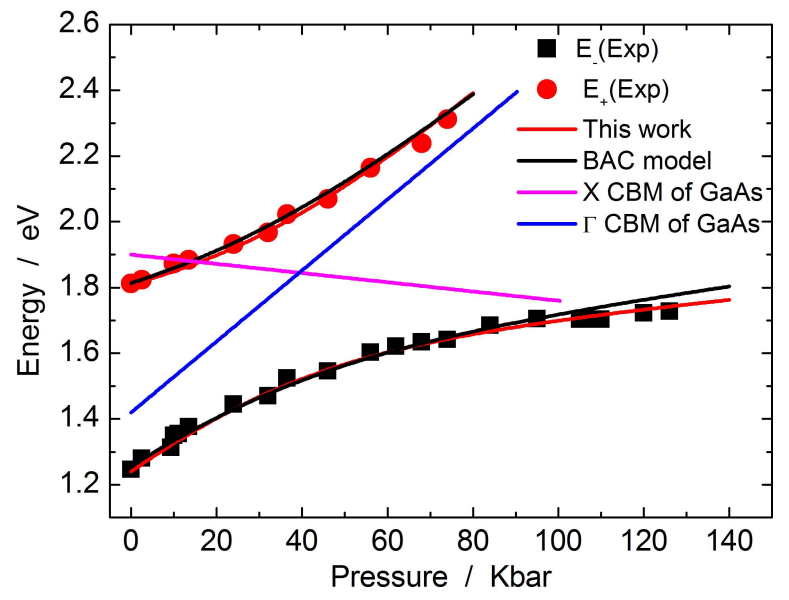

Fig. 1. Pressure dependence of $\mathrm{E}_{+}$and $\mathrm{E}_{-}$for the dilute nitride $\mathrm{GaN}_{\mathrm{x}} \mathrm{As}_{1-\mathrm{x}}$. The experimental data are from the literature [11].

If we want to explain the pressure dependence of $\mathrm{E}_{+}$and $\mathrm{E}_{-}$, we must understand the coupling interactions in $\mathrm{GaN}_{\mathrm{x}} \mathrm{As}_{1-\mathrm{x}}$. It is well known that there are three coupling interactions (the impurityhost interaction, the impurity-impurity interaction and the host-host interaction) in $\mathrm{GaN}_{\mathrm{x}} \mathrm{As}_{1-\mathrm{x}}$. As the band evolution of the dilute nitride alloys is determined by the three coupling interactions, the best way to describe the pressure dependence of the band gap energy of the dilute nitride $\mathrm{GaN}_{\mathrm{x}} \mathrm{As}_{1-\mathrm{x}}$ is to take into account the three coupling interactions.

For $\mathrm{GaN}_{0.015} \mathrm{As}_{0.985}$, we consider that the deviation of the linearity for $\mathrm{E}_{+}$and $\mathrm{E}_{-}$is due to the coupling interaction between $\mathrm{E}_{+}$and $\mathrm{E}_{-}$. The reason is as follows. (1) For $\mathrm{GaN}_{0.015} \mathrm{As}_{0.985}$, the alloy states $\mathrm{E}_{+}$and $\mathrm{E}_{-}$should be very stable. The energy levels which the localized and extended states correspond to cannot be filtered from both of them by applying pressure. When the pressure is introduced to change the interaction between the bands, both $\mathrm{E}_{+}$and $\mathrm{E}_{-}$will interact with other bands as an individual band. (2) If the deviation of the linearity for $\mathrm{E}_{+}$and $\mathrm{E}_{-}$is considered to be due to the coupling interaction between $\mathrm{E}_{+}$and $\mathrm{E}_{-}$, three coupling interactions in $\mathrm{GaN}_{\mathrm{x}} \mathrm{As}_{1-\mathrm{x}}$ are taken into account 
because the alloy states which $\mathrm{E}_{+}$and $\mathrm{E}_{-}$correspond to include the $\mathrm{N}$ state and the perturbed host state.

Based on this analysis, we consider that the pressure can influence the band $\mathrm{E}_{+}$and $\mathrm{E}_{-}$from two aspects. On the one hand, the pressure can lead to $\mathrm{E}_{+}$and $\mathrm{E}_{-}$increasing similar to the bands in the conventional semiconductors. On the other hand, the hybridization effect between the states (which $\mathrm{E}_{+}$and $\mathrm{E}_{-}$corropond to) becomes obvious when the pressure increases. The effect can push $\mathrm{E}_{+}$up and $\mathrm{E}_{-}$down, leading to $\mathrm{E}_{+}$increasing superlinearly and $\mathrm{E}_{-}$increasing sublinearly. As the hybridization effect is due to the pressure, the coupling interaction between $\mathrm{E}_{+}$and $\mathrm{E}_{-}$should be dependent on pressure. When the pressure becomes large, the coupling interaction between them should increase.

Based on the above analysis, several assumptions are made: (1) Without considering the coupling interaction between $\mathrm{E}_{+}$and $\mathrm{E}_{-}$, the bands $\mathrm{E}_{+}$and $\mathrm{E}_{-}$increase linearly with increasing pressure. (2) The deviation of the linearity for $E_{+}$ and $\mathrm{E}_{-}$is due to the coupling interaction between them. (3) The coupling interaction between $E_{+}$and E_depending on pressure can be in analogy to the coupling interaction between the $\mathrm{N}$ level and the $\Gamma$ $\mathrm{CBM}$ of the host material depending on $\mathrm{N}$ content in the BAC model.

Based on the assumption (1), $\mathrm{E}_{+,(\mathrm{P})}$ and $\mathrm{E}_{-,(\mathrm{P})}$ without considering the coupling interaction between $\mathrm{E}_{+}$and $\mathrm{E}_{-}$can be given as follows:

$$
\begin{aligned}
& E_{+,(P)}=E_{+}(0)+\alpha P s \\
& E_{-,(P)}=E_{-}(0)+\beta P
\end{aligned}
$$

where $\mathrm{E}_{+}(0)$ is the energy of $\mathrm{E}_{+}$at $0 \mathrm{GPa}$ and $\mathrm{E}_{-}(0)$ is the energy of $\mathrm{E}_{-}$at $0 \mathrm{GPa} . \alpha$ and $\beta$ are pressure coefficients for $\mathrm{E}_{+}$and $\mathrm{E}_{-}$without considering the coupling interaction between $\mathrm{E}_{+}$and $\mathrm{E}_{-}$, respectively.

Based on the assumption (2), the matrix can be given in the following expression:

$$
\left|\begin{array}{ll}
E_{+,(P)}-E & V \\
V & E_{-,(P)}-E
\end{array}\right|=0
$$

where $\mathrm{V}$ is the matrix element coupling $\mathrm{E}_{+}$and $\mathrm{E}_{-}$. In the BAC model, the coupling interaction between the $\mathrm{N}$ level and the $\Gamma \mathrm{CBM}$ of the host material depending on $\mathrm{N}$ content can be given in the following equation:

$$
V=C_{M N} \sqrt{x}
$$

where $\mathrm{C}_{\mathrm{MN}}$ is the coupling constant and $\mathrm{x}$ is the $\mathrm{N}$ content. Based on the assumption (3), the coupling interaction between $\mathrm{E}_{+}$and $\mathrm{E}_{-}$can be given in the following form:

$$
V=C_{E_{+}-E_{-}} \sqrt{\frac{P}{P_{0}}}
$$

where $\mathrm{C}_{\mathrm{E}_{+}-\mathrm{E}_{-}}$is a parameter which describes the coupling strength between $\mathrm{E}_{+}$and $\mathrm{E}_{-}$. It can be determined by fitting the experimental data. $\mathrm{P}_{0}$ is an empirical parameter. In this work, $\mathrm{P}_{0}=50 \mathrm{GPa}$ is used.

Based on equation 1, equation 2, equation 3 , and equation 5 , two solutions can be written as:

$$
\begin{aligned}
& E(P)_{ \pm}=\frac{1}{2}\left[E_{+(0)}+\alpha P+E_{-(0)}+\beta P\right. \\
& \left. \pm \sqrt{\left(E_{+(0)}+\alpha P-E_{-(0)}-\beta P\right)^{2}+4\left(C_{E_{+}-E_{-}}\right)^{2} \frac{P}{P_{0}}}\right]
\end{aligned}
$$

We use the model to fit the experimental data of $\mathrm{E}_{+}$and $\mathrm{E}_{-}$for $\mathrm{GaN}_{0.015} \mathrm{As}_{0.985}$. In this work, $\mathrm{E}_{-(0)}$ and $\mathrm{E}_{+(0)}$ are obtained according to the experimental data. Here $\mathrm{E}_{-(0)}=1.24 \mathrm{eV}$ and $\mathrm{E}_{+(0)}=1.81 \mathrm{eV}$ are used [11]. The best agreement with the experimental data, as denoted by solid lines in Fig. 1, is obtained by setting $\alpha=1.0 \times 10^{-2} \mathrm{eV} / \mathrm{GPa}$, $\beta=1.2 \times 10^{-1} \mathrm{eV} / \mathrm{GPa}$ and $\mathrm{C}_{\mathrm{E}_{+}-\mathrm{E}_{-}}=2.7 \mathrm{eV}$ in the model. We also used the BAC model to fit the experimental data. The result for the BAC model is also shown in Fig. 1. Compared with the BAC model, it can be seen that the model developed in this work can describe the experimental data better. The pressure coefficient for $\mathrm{E}_{-}$shows that if the hybridization effect is not taken into account, the $\Gamma$ conduction band of $\mathrm{GaN}_{\mathrm{x}} \mathrm{As}_{1-\mathrm{x}}$ is extended. The small pressure coefficient for $\mathrm{E}_{+}$may be due to the influence of the $\mathrm{N}$ level as the location of $\mathrm{E}_{+}$ is very close to the isolate $\mathrm{N}$ level. 
The $\Gamma \mathrm{CBM}$ and the X CBM of GaAs depending on pressure are also shown in Fig. 1. It can be seen that the $\Gamma \mathrm{CBM}$ of GaAs moves up to higher energy rapidly with increasing pressure while the X CBM of GaAs moves down to lower energy. The energy difference between the $\Gamma \mathrm{CBM}$ of GaAs and the X CBM of GaAs becomes small with increasing pressure. When the pressure is large enough, the energy difference between them becomes zero. Under this condition, if the pressure goes on increasing, the $\mathrm{X} \mathrm{CBM}$ of GaAs will be lower than the $\Gamma \mathrm{CBM}$ of GaAs and the band gap of GaAs will change from the direct band to the indirect band gap. It is reported that the pressure which the crossover between the X CBM of $\mathrm{GaAs}$ and the $\Gamma \mathrm{CBM}$ of $\mathrm{GaAs}$ corresponds to is $3.9 \mathrm{GPa}$ to $4.2 \mathrm{GPa}$ [12-15]. For $\mathrm{GaN}_{\mathrm{x}} \mathrm{As}_{1-\mathrm{x}}$, it is found that when the pressure does not exceed $12 \mathrm{GPa}, \mathrm{GaN}_{\mathrm{x}} \mathrm{As}_{1-\mathrm{x}}$ still has a direct band gap, which shows that $\mathrm{GaN}_{\mathrm{x}} \mathrm{As}_{1-\mathrm{x}}$ needs much larger pressure than GaAs to realize the transition from the direct band gap to the indirect band gap. It is due to two factors. One is the coupling interaction between the $\mathrm{E}_{+}$and $\mathrm{E}_{-}$. The other is that the energy difference between the X CBM and the $Г$ CBM in GaNAs is larger than that in GaAs.

Let us examine the first factor in great detail. Usually, the pressure dependence of the X CBM is much weaker than that of the $\Gamma \mathrm{CBM}$ so the difference of the pressure dependence between the $\mathrm{X}$ CBM of GaNAs and the X CBM of GaAs should be small. However, it is found that the pressure dependence of the $\Gamma \mathrm{CBM}$ for GaNAs is much weaker than that for GaAs. The reason is as follows. In $\mathrm{GaAs}, \mathrm{E}_{+}$does not exist so there is no $\mathrm{E}_{+}$to influence the movement of the $\Gamma \mathrm{CBM}$ of GaAs. In $\mathrm{GaN}_{\mathrm{x}} \mathrm{As}_{1-\mathrm{x}}$, the $\Gamma \mathrm{CBM}$ of $\mathrm{GaN}_{\mathrm{x}} \mathrm{As}_{1-\mathrm{x}}$ increases more slowly with increasing pressure than that of GaAs due to the coupling interaction between $\mathrm{E}_{+}$ and $\mathrm{E}_{-}$.

It is an interesting question why the energy difference between the $\mathrm{X} \mathrm{CBM}$ and the $\Gamma \mathrm{CBM}$ in $\mathrm{GaN}_{\mathrm{X}} \mathrm{As}_{1-\mathrm{X}}$ is larger than that in GaAs. It is due to the impurity-host interaction. We know that the incorporation of $\mathrm{N}$ dopant in GaAs introduces a localized $\mathrm{N}$ level. When the $\mathrm{N}$ content is large, the coupling interaction between the localized $\mathrm{N}$ level and the $\Gamma \mathrm{CBM}$ of GaAs is very large. Because of the strong coupling interaction between them, the $\Gamma \mathrm{CBM}$ of $\mathrm{GaN}_{\mathrm{x}} \mathrm{As}_{1-\mathrm{x}}$ will be pushed down as the energy of the $\Gamma \mathrm{CBM}$ of GaAs is lower than that of the $\mathrm{N}$ level. For the $\mathrm{X} \mathrm{CBM}$ of $\mathrm{GaN}_{\mathrm{x}} \mathrm{As}_{1-\mathrm{x}}$, we know that it evolves from the $\mathrm{X}$ CBM of GaAs. In studying $\mathrm{GaN}_{\mathrm{x}} \mathrm{P}_{1-\mathrm{x}}$ alloy, it is found that the coupling interaction exists between the $\mathrm{N}$ level and the X CBM of GaP [16-18]. As $\mathrm{GaN}_{\mathrm{x}} \mathrm{As}_{1-\mathrm{x}}$ alloy is similar to $\mathrm{GaN}_{\mathrm{x}} \mathrm{P}_{1-\mathrm{x}}$ alloy, the coupling interaction should also exist between the $\mathrm{X}$ CBM of GaAs and the $\mathrm{N}$ level. As the X CBM of GaAs lies above the $\mathrm{N}$ level, the coupling interaction between them should inhibit the decline of the X CBM of $\mathrm{GaN}_{\mathrm{x}} \mathrm{As}_{1-\mathrm{x}}$, leading to the X CBM of $\mathrm{GaN}_{\mathrm{x}} \mathrm{As}_{1-\mathrm{x}}$ decreasing more slowly than the $\Gamma$ $\mathrm{CBM}$ of $\mathrm{GaN}_{\mathrm{x}} \mathrm{As}_{1-\mathrm{x}}$. This is the reason for that the energy difference between the X CBM and the $\Gamma$ $\mathrm{CBM}$ in $\mathrm{GaN}_{\mathrm{x}} \mathrm{As}_{1-\mathrm{x}}$ is larger than that in GaAs.

It should be pointed out that the pressure dependence of the band gap for $\mathrm{GaN}_{\mathrm{x}} \mathrm{As}_{1-\mathrm{x}}$ is very different from that for $\mathrm{GaN}_{\mathrm{x}} \mathrm{P}_{1-\mathrm{x}}$ [16]. For the dilute nitride $\mathrm{GaN}_{\mathrm{x}} \mathrm{P}_{1-\mathrm{x}}$, as the energy difference between the $\mathrm{X} C \mathrm{CBM}$ of GaNP and the $\Gamma \mathrm{CBM}$ of $\mathrm{GaN}_{\mathrm{x}} \mathrm{P}_{1-\mathrm{x}}$ is very small, it does not need large pressure to realize the transition from direct to indirect band gap. The small energy difference between the X CBM and the $\Gamma \mathrm{CBM}$ in GaNP is mainly due to that the $\Gamma$ $\mathrm{CBM}$ of $\mathrm{GaN}_{\mathrm{x}} \mathrm{P}_{1-\mathrm{x}}$ evolves from the $\mathrm{N}$ level while the location of the $\mathrm{N}$ level in $\mathrm{GaP}$ is close to the $\mathrm{X}$ $\mathrm{CBM}$ of GaP.

\section{Conclusions}

In conclusion, we analyze the band evolution of the dilute nitride $\mathrm{GaN}_{\mathrm{x}} \mathrm{As}_{1-\mathrm{x}}$. It is found that the sublinear pressure dependence of the band gap energy is due to the coupling interaction between $\mathrm{E}_{+}$ and $\mathrm{E}_{-}$. A model is developed to describe the pressure dependence of the band gap energy. The model may be used to describe the pressure dependence of the band gap energy for other dilute nitride alloys. We also find that it needs much larger pressure for $\mathrm{GaN}_{\mathrm{x}} \mathrm{As}_{1-\mathrm{x}}$ than for $\mathrm{GaAs}$ to realize the transition from the direct band gap to the indirect band gap. It is due to two factors. One is the coupling 
interaction between the $\mathrm{E}_{+}$and $\mathrm{E}_{-}$. The other is that the energy difference between the X CBM and the $\Gamma \mathrm{CBM}$ in GaNAs is larger than that in GaAs.

\section{Acknowledgements}

This work is supported by the National Nature Science Foundation of China (61504094).

\section{References}

[1] Uesugi K., Marooka N., Suemune I., Appl. Phys. Lett., 74 (1999), 1254.

[2] Zhao C.Z., Li N.N., Wei T., Tang C.X., Chin. Phys. Lett., 28 (2011), 127801.

[3] Klar P.J., Grüning H., Heimbrodt W., Koch J., Höhnsdorf F., Stolz W., Vicente P.M.A., CAMASSEl J., Appl. Phys. Lett., 76 (2000), 3439.

[4] Uesugi K., Suemune I., Hasegawa T., AkutaGawa T., Nakamura T., Appl. Phys. Lett., 76 (2000), 1285.

[5] Deng H.X., Li J., Li S.S., Peng H., Xia J.B., Wang L.W., WeI S.H., Phys. Rev. B, 82 (2010), 193204.

[6] Seong M.J., Mascarenhas A., Geisz J.F., Appl. Phys. Lett., 79 (2001), 1297.

[7] Francoeur S., SeOng M.J., Hanna M.C., Geisz J.F., Mascarenhas A., Xin H.P., Tu C.W., Phys. Rev. B, 68 (2003), 075207.

[8] Timoshevski V., Côté M., Gilbert G., LeOnelli R., TuRcotte S., BeAudry J.N., Desjardins P., Larouche S., Martinu L., Masut R.A., Phys. Rev. B, 74 (2006), 165120.
[9] Merrick M., Cripps S.A., Murdin B.N., Hosea T.J.C., Veal T.D., Mcconville C.F., Phys. Rev. B, 76 (2007), 075209.

[10] Weinstein B.A., Stambach S.R., Ritter T.M., Maclean J.O., Wallis D.J., Phys. Rev. B, 68 (2003), 035336.

[11] Shan W., Walukiewicz W., Ager III J.W., Haller E.E., Geisz J.F., Friedman D.J., Olson J.M., KurTz S.R., J. Appl. Phys., 86 (1999), 2349.

[12] Wolford D.J., Bradley J.A., Fry K., ThompSON J., The Nitrogen Isoelectronic Trap in GaAs, in: Chadi J.D., Harrison W.A., (Eds.), Physics of Semiconductors, Springer, New York, 1984, p. 627.

[13] Goni A.R., Strossner K., Syassen K., Cardona M., Phys. Rev. B, 36 (1987), 1581.

[14] Wang W.J., Su F.H., Ding K., Li G.H., Yoon S.F., FAn W.J., Wicaksono S., Ma B.S., Phys. Rev. B, 74 (2006), 195201.

[15] Tsang M.S., Wang J.N., Ge W.K., Li G.H., FAnG Z.L., Chen Y., Han H.X., Li L.H., Pan Z., Appl. Phys. Lett., 78 (2001), 3595

[16] Wu J., Walukiewicz W., Yu K.M., Ager III J.W., Haller E.E., Hong Y.G., Xin H.P., Tu C.W., Phys. Rev. B, 65 (2002), 241303(R).

[17] Zhao C.Z., Wei T., Sun X.D., Wang S.S., LU K.Q., J. Alloy. Compd., 608 (2014), 66.

[18] ZhaO C.Z., Wei T., Li N.N., WANG S.S., LU K.Q., J. Appl. Phys., 116 (2014), 063512.

Received 2016-05-04 Accepted 2016-09-25 